Available online at GSC Online Press Directory

GSC Biological and Pharmaceutical Sciences

e-ISSN: 2581-3250, CODEN (USA): GBPSC2

Journal homepage: https://www.gsconlinepress.com/journals/gscbps

(RESEARCH ARTICLE)

\title{
Chemical evaluation, bioactive compounds and antioxidant activity of Rosa rubiginosa L. fruit and seed
}

\author{
Jofré María, Razzeto Gabriela, Escudero Nora *and Albarracín Graciela \\ Faculty of Chemistry, Biochemistry and Pharmacy, National University of San Luis, Ejército de los Ándes 950, San Luis, \\ Argentina, 5700.
}

Publication history: Received on 01 November 2017; revised on 27 November 2017; accepted on 18 December 2017

https://doi.org/10.30574/gscbps.2017.1.3.0055

\begin{abstract}
Knowledge on foods nutritional composition, in particular vegetables and fruits, plays a significant role in human diet, given that they are important sources of bioactive and antioxidant compounds. Currently, their consumption has increased due to physiological benefits and/or diseases risk reduction. The goal of the present study is to evaluate the chemical-nutritional composition, bioactive components and antioxidant activity of the seed ( $\mathrm{M}_{\mathrm{s}}$ ), seedless fruit (MF/s) and whole fruit $\left(\mathrm{M}_{\mathrm{F}}\right.$ ) of Rosa rubiginosa (Rosa eglanteria L.) from San Luis, Argentina, and their eventual application as functional foods. In Ms, the content of proteins, fatty matter and crude fiber is higher than in the other parts analyzed $\left(4.35 \pm 0.05,7.69 \pm 0.55\right.$ and $11.66 \pm 0.28 \mathrm{~g} / 100 \mathrm{~g}$, respectively); and $\mathrm{M}_{\mathrm{F} / \mathrm{s}}$ presents the highest ash content, $7.11 \pm 0.06 \%$. It is noted the high linoleic acid content (43.10-37.61\%), followed by $\alpha$-linolenic (32.63-28.64\%) and oleic (15.41$16.92 \%)$ acid in $M_{S}$ and $M_{F}$, respectively. The values of total phenols obtained for $M_{F}$ and $M_{F / S}(119.11 \pm 1.58$ and 116.21 $\pm 2.12 \mathrm{mg} / 100 \mathrm{~g} \mathrm{dw}$ of gallic acid) are significantly higher than for Ms. Regarding the antioxidant activity measured by DPPH, the inhibition percentage does not present significant differences among the three studied samples 93.37, 93.76 and $93.47 \%$, which are values considered as with high radical scavenging activity. The obtained results are a contribution to the knowledge on the nutritional properties and antioxidant activity of $R$. rubiginosa fruit and seed, which would allow diversifying their consumption and be considered as an emerging nutritional food.
\end{abstract}

Keywords: Sweet briar Rose; Rosa rubiginosa; Chemical Composition; Total Phenols; Antioxidant activity

\section{Introduction}

The increasing population in the developing word has driven the demand of foods and other agricultural products up to extraordinary ranks. The Food and Agriculture Organization (FAO) has calculated that in order to satisfy the foods demand in 2050, the worldwide annual agricultural and livestock production will have to be $60 \%$ higher than in 2006 [1]. Analyzing the current food sources, it has to be assumed that these requirements will have to be covered by unconventional nutritional sources.

Non-communicable diseases (NCDs) (ENT) are the result of the combination of several factors, such as genetic, physiological, behavioral and environmental factors. They mainly affect low and medium income countries, where more than $75 \%$ of deaths are due to these diseases [2].

From the nutritional point of view, the main function of the diet is to provide the nutrients required to satisfy the metabolic and functional demands of people. This traditional concept has changed in the recent years, when considering the diet as the first line of defense against these diseases. Thus, resulting in the concept of "functional food", defined as

\footnotetext{
${ }^{*}$ Corresponding author

E-mail address: nlesc@ unsl.edu.ar
}

Copyright (C) 2017 Author(s) retain the copyright of this article. This article is published under the terms of the Creative Commons Attribution Liscense 4.0. 
modified foods or foods containing ingredients that show actions that improve the well-being of the individual, or that decrease the diseases risks, beyond the traditional function of the ingredients they contain [3], while the International Life Science Institute (ILSI) [4] defines them as foods that thanks to the presence of physiologically active components, provide health benefits beyond the classical action of the ingredients they contain.

Plant materials contain a wide diversity of bioactive compounds, among which are the antioxidants. These have been widely studied in the last decades due to their functional properties, having applications in health, cosmetic and food industries [5]. Fruits as foods are a potential source of antioxidants and provide nutrients. The elevated consumption of fruits has a positive impact on health, due to the presence of metabolites capable of neutralizing reactive oxygen species (ROS) [6]. Currently, there has been a renewed interest in the study of the chemical composition of fruits and seeds of wild native plants, both from Latin America as well as form Africa and Asia, given that these continents have the highest biodiversity worldwide, which is a subject that has been the central focus of recent scientific meetings.

Rosaceae are dicotyledonous plants that belong to the Rosales order; they include the majority of the massive consumption species: apple, pear, quince, peach, plum, cherry, strawberry, almond, etc. They have been used for a long time for nutritional and medical purposes. Regarding the portions of the different wild rose species identified in Argentina, it has been estimated that $90 \%$ corresponds to Rosa rubiginosa, $8 \%$ to Rosa canina and $2 \%$ to Rosa moschata [7]. R. rubiginosa (Rosa eglanteria L.), common name "sweet briar rose", belongs to the Rosaceae family. It is an exotic shrub species that has invaded large extensions of land in the Andean Patagonian region. Fruits from rose plants (Rosa $\mathrm{sp}$ ) contain several bioactive compounds, they are rich in polyphenols, essential fatty acids, vitamins and minerals, among others [8-10].

Taking into account the importance of fruits and seeds of wild plants, and the lack of information regarding their nutritional value, the goal of this work is to evaluate the chemical-nutritional composition, bioactive compounds and antioxidant activity of the seed $\left(\mathrm{M}_{\mathrm{S}}\right)$, seedless fruit $\left(\mathrm{M}_{\mathrm{F} / \mathrm{S}}\right)$ and whole fruit $\left(\mathrm{M}_{\mathrm{F}}\right)$ of $R$. rubiginosa (Rosa eglanteria L.) from the Central Saws of San Luis Province, Argentina, and their eventual application as functional food.

\section{Materials and methods}

\subsection{Chemicals}

Unless stated otherwise, all chemicals were from Sigma. Folin-Ciocalteu reagent and gallic acid (Anedra, Buenos Aires, Argentina), Griess reagent (Britania, Argentina) and buthylated hydroxyl toluene (BHT) (Merck, USA).

\subsection{Plant materials}

The $R$. rubiginosa L. fruits are from the Central Saws of San Luis Province, Argentina, and were collected during March 2016.

\subsection{Flour preparation}

Work was performed with different parts of the fruit (Ms: seed, MF/s: seedless fruit and MF: whole fruit), which were dried in a forced-air oven at $40-45^{\circ} \mathrm{C}$ for $72 \mathrm{~h}$. The product was then subjected to dry grinding in an electric grinder (CG-8 Stylo, $220 \mathrm{~V}-50 \mathrm{~Hz} 90 \mathrm{~W}$, China) and sieved through $200 \mu \mathrm{m}$ nylon. The flour was stored in a sealed airtight container away from light at $4{ }^{\circ} \mathrm{C}$. Analyzes were performed in triplicate and the mean value was expressed by dry matter.

\subsection{Proximate chemical composition}

Proteins, lipids, moisture, ashes and dietary fiber determinations were performed according to the methodology proposed by the Official Methods of Analysis [11]. Carbohydrates concentrations were calculated by difference.

\subsection{Determination of fatty acids profile}

The analysis was performed by gas chromatography, after lipids extraction and saponification to release the fatty acids and form the methyl esters, which are then separated and quantified by AOCS Ce 1k-09 [12].

\subsection{Extraction of total phenols}

The flours from the different parts of $R$. rubiginosa L. were defatted. Lipid extraction was performed by refluxing the samples in hexane in a Soxhlet apparatus for $10 \mathrm{~h}$. The hexane was evaporated, and then the samples were stored at 5 
${ }^{\circ} \mathrm{C}$. Extraction of total phenols was carried out from $50 \mathrm{mg}$ of defatted sample with $5 \mathrm{~mL}$ of $1.2 \mathrm{~mol} / \mathrm{L} \mathrm{HCl}$ in methanol:water at $50 \%$. The sample was heated at $90{ }^{\circ} \mathrm{C}$ for $3 \mathrm{~h}$ with vortexing every $30 \mathrm{~min}$. Afterwards, the sample was cooled down to room temperature and diluted to $10 \mathrm{~mL}$ with methanol, and subsequently centrifuged for $5 \mathrm{~min}$ at $5000 \mathrm{~g}$. The supernatant was used for phenols, flavonoids, anthocyanins and antioxidant activity determinations [13].

\subsection{Total phenols}

The determination of total phenols was performed by measuring the absorbance at $750 \mathrm{~nm}$ using Folin Ciocalteu reagent with gallic acid as a standard, and expressed as $\mathrm{mg} / 100 \mathrm{~g}$ of dry weight ( $\mathrm{dw}$ ) of gallic acid equivalent. Aliquots of $0.5 \mathrm{~mL}$ of standard, distilled water (blank) and methanolic extract, were added to flasks containing $4.5 \mathrm{~mL}$ of distilled water; subsequently, they were mixed with $0.5 \mathrm{~mL}$ of the Folin-Ciocalteu reagent and $5 \mathrm{~mL}$ of $7 \%$ sodium carbonate. The total volumes were filled to $12.5 \mathrm{~mL}$ with distilled water. The mixture was allowed to stand for $90 \mathrm{~min}$ at room temperature before measuring the absorbance at $750 \mathrm{~nm}$ (UV-Vis BeckmanDK-2 ${ }^{\mathrm{a}}$ ) [14].

\subsection{Anthocyanins}

Anthocyanins were estimated by a $\mathrm{pH}$ differential method [15]. Anthocyanins are natural pigments that undergo reversible structural transformations between $\mathrm{pH} 1.0$ to $\mathrm{pH} 4.5$. At $\mathrm{pH}$ 1.0, anthocyanins exist as colored oxonium or flavylium, and at $\mathrm{pH} 4.5$, the carbinol form (the one with less color) prevails. Two aliquots of an aqueous anthocyanin solution are used, one adjusted to $\mathrm{pH} 1.0$ and one to $\mathrm{pH} \mathrm{4.5,} \mathrm{respectively.} \mathrm{The} \mathrm{difference} \mathrm{in} \mathrm{absorbance} \mathrm{at} 510 \mathrm{~nm}$ is proportional to the anthocyanin content. Moreover, measuring at $700 \mathrm{~nm}$ includes interfering substances and degraded anthocyaninic derivates. Two buffers systems are used: $\mathrm{pH} 1.0$ (chloride acid/potassium chloride (buffer 1) and $\mathrm{pH} 4.5$ (acetic acid/sodium acetate (buffer 2). Buffer 1 is prepared with $\mathrm{KCl} 0.025 \mathrm{M}$ and adjusted at $\mathrm{pH} 1.0$ with $\mathrm{HCl}$, and buffer 2 consists of a $0.4 \mathrm{M}$ acetic acid/sodium acetate solution. Methanolic extract (1 $\mathrm{mL})$ from the sample was added with 2 $\mathrm{mL}$ of buffer 1, and another aliquot with $2 \mathrm{~mL}$ of buffer 2 . Absorbance was measured in a spectrophotometer (UV-Vis Beckman DK-2 ${ }^{\mathrm{a}}$ ) at $510 \mathrm{~nm}$ and $700 \mathrm{~nm}$ in buffers 1 and 2 , at $\mathrm{pH} 1.0$ and 4.5, respectively, using:

$\mathrm{A}=\left[\left(\mathrm{A}_{510}-\mathrm{A}_{700}\right) \mathrm{pH} 1.0-\left(\mathrm{A}_{510}-\mathrm{A}_{700}\right) \mathrm{pH} 4.5\right]$

Monomeric pigment concentration in the extract is expressed in cyanidin-3-glucoside. Results were expressed as $\mathrm{mg} / 100 \mathrm{~g} \mathrm{dw}$.

Monomeric anthocyanin $(\mathrm{mg} / 100 \mathrm{~g})=(\mathrm{A} \times \mathrm{MW} \times \mathrm{DF}) / \varepsilon$

$\mathrm{A}=$ Absorbance; $\mathrm{MW}=$ Molecular weight: 449.2; $\mathrm{DF}=$ Dilution factor; $\varepsilon=$ Molar extinction coefficient 26,900

\subsection{DPPH free radical scavenging assay}

This method reflects the sample capacity to inhibit the action of free radicals generated by DPPH, in a highly polar environment, in the absence of an oxidable lipid. The hydrogen atoms, or electrons donation ability, of the extract under study was measured based on the bleaching of a DPPH purple-colored MeOH solution. This spectrophotometric assay uses the stable radical 1, 1-diphenyl-2-picrylhydrazyl (DPPH) as reagent [16]. Various concentrations of the extract in $\mathrm{MeOH}(50 \mu \mathrm{L})$ were added to $5 \mathrm{~mL}$ of a $0.004 \% \mathrm{MeOH}$ solution of DPPH. After a 30 min incubation period at room temperature, the measurement of absorbance was performed against a blank at $517 \mathrm{~nm}$ (UV-VisBeckmanDK-2 ${ }^{\mathrm{a}}$ ). The blank contained all reagents except the tested compound. The synthetic antioxidant butylated hydroxytoluene (BHT) was included in the experiments as a positive control $(1.6 \mu \mathrm{g} / \mathrm{mL})$. The percentage (\%) of DPPH scavenging was calculated using the following equation:

$\%$ DPPH Scavenging $=($ Ablank - Asample $/$ Ablank $) \times 100$

A $=$ Absorbance

\subsection{0. $\beta$ - carotene-linoleic acid assay}

This technique involves measuring $\beta$-carotene bleaching at $470 \mathrm{~nm}$, resulting from the $\beta$-carotene oxidation through linoleic acid degradation products. Tween is used for the dispersion of linoleic acid and $\beta$-carotene [17]. $\beta$-carotene $(0.2$ $\mathrm{mg}$ ) was dissolved in $0.2 \mathrm{~mL}$ of chloroform and then added to round-bottom flasks ( $50 \mathrm{~mL}$ ) containing $0.02 \mathrm{~mL}$ of linoleic acid and $0.2 \mathrm{~mL}$ of tween 20 . A vacuum evaporator was used to completely remove the chloroform present in the solution. Then, $50 \mathrm{~mL}$ of distilled water were added with vigorous shaking ( $40 \mathrm{~min})$. This reaction mixture $(3 \mathrm{~mL})$ was dispersed into test tubes that contained a $200 \mu \mathrm{L}$ portion of the sample extracts $(5 \mathrm{mg} / \mathrm{mL})$. The same procedure was repeated with synthetic antioxidant BHT $(100 \mu \mathrm{g} / \mathrm{mL})$ as positive control and with methanol as negative control. The 
mixtures were shaken for $2 \mathrm{~min}$ and then the test tubes were placed in a water bath at $50{ }^{\circ} \mathrm{C}$; the absorbance was measured at $470 \mathrm{~nm}$ at time zero $(\mathrm{t}=0)$. The measurement of absorbance was continued at intervals of 15 min until the color of $\beta$-carotene disappeared in the control tubes $(t=60 \mathrm{~min})$. A mixture prepared as above but without $\beta$-carotene was used as blank. The extracts antioxidant activity (AA) was evaluated in terms of $\beta$-carotene bleaching and expressed as percentage (\%), calculated by the following equation:

$\%$ bleaching $\beta$-carotene $=100 \times\left[1-\left(\mathrm{A}_{0}-\mathrm{A}_{\mathrm{t}} / \mathrm{A}^{\circ}{ }_{0}-\mathrm{A}^{\circ} \mathrm{t}\right)\right]$

Where, $\mathrm{A}_{0}$ and $\mathrm{A}^{\circ}$ correspond to the absorbance values measured at $\mathrm{t}=0$ of incubation for the samples and control, respectively.

$A_{t}$ and $\mathrm{A}^{\circ}$ are the absorbance values measured at the end of the incubation period for the samples and control, respectively, when the control becomes completely bleached (60 $\mathrm{min})$.

\subsection{Scavenging activity against nitric oxide (NO test)}

Nitric oxide was generated from sodium nitroprusside and measured by Griess reaction [18, 19]. Sodium nitroprusside in aqueous solution and at physiological $\mathrm{pH}$, generates nitric oxide spontaneously, which then interacts with oxygen to produce nitrite ions, which can then be estimated using Griess reagent, with which nitrite reacts to give a stable product that absorbs at $542 \mathrm{~nm}$. Scavengers of nitric oxide compete with oxygen leading to a reduced production of nitrite. A sodium nitroprusside solution was prepared immediately before the experiment by dissolving $10 \mathrm{mmol} / \mathrm{L} \mathrm{sodium}$ nitroprusside in $0.02 \mathrm{~mol} / \mathrm{L}$ phosphate buffer, $\mathrm{pH}$ 7.4, which was bubbled with argon beforehand. The samples were diluted in $0.02 \mathrm{~mol} / \mathrm{L}$ phosphate buffer, $\mathrm{pH} 7.4$, to obtain optimal concentrations. The experiment comprised diluting 1 $\mathrm{mL}$ of the samples $(2.5 \mathrm{mg} / \mathrm{mL})$ with $1 \mathrm{~mL}$ of sodium nitroprusside solution and incubated at room temperature for 150 min. At the end of the incubation period, $2 \mathrm{~mL}$ of Griess reagent (1\% sulphanilamide, $2 \% \mathrm{H}_{3} \mathrm{PO}_{4}$ and $0.1 \%$ naphthylehylenediamine dihydrochloride) were added to each sample, and the absorbance was read at $542 \mathrm{~nm}$ (UVVisBeckmanDK-2 ${ }^{-}$). A blank without test extract, but with equivalent amount of methanol, was conducted in an identical manner. Nitrite concentration was calculated by referring to the absorbance of standard solutions of sodium nitrite.

Results were expressed as percentage (\%) of nitrite production with respect to the blank.

$\%$ Nitrite Production $=\left[\left(A_{\text {blank }}-A_{\text {sample }}\right) / A_{\text {blank }}\right] \times 100$

A=Absorbance

\section{Results and discussion}

Knowledge on the nutritional composition of foods, in particular vegetables and fruits, plays a very important role in human nutrition. Therefore, they are important sources of bioactive and antioxidant compounds.

Table 1 Proximate chemical composition of R. rubiginosa L. flour (g/100 g)

\begin{tabular}{lccc}
\hline Determination (g/100 g) & Ms & $\mathbf{M}_{\mathbf{F} / \mathbf{s}}$ & $\mathbf{M}_{\mathbf{F}}$ \\
\hline Moisture & $3.62 \pm 0.04^{\mathrm{a}}$ & $9.82 \pm 0.21^{\mathrm{b}}$ & $5.99 \pm 0.19^{\mathrm{c}}$ \\
Ashes & $1.57 \pm 0.01^{\mathrm{a}}$ & $7.11 \pm 0.06^{\mathrm{b}}$ & $4.09 \pm 0.18^{\mathrm{c}}$ \\
Proteins (N x 6.25) & $4.35 \pm 0.05^{\mathrm{a}}$ & $3.30 \pm 0.07^{\mathrm{b}}$ & $4.01 \pm 0.22^{\mathrm{a}}$ \\
Fatty matter & $7.69 \pm 0,55^{\mathrm{a}}$ & $1.3 \pm 0.13^{\mathrm{b}}$ & $4.65 \pm 1.59^{\mathrm{a}}$ \\
Crude fiber & $11.66 \pm 0.28^{\mathrm{a}}$ & $6.73 \pm 0.13^{\mathrm{b}}$ & $6.68 \pm 0.21^{\mathrm{b}}$ \\
Total carbohydrates ${ }^{1}$ & $82.76 \pm 0.66^{\mathrm{a}}$ & $78.46 \pm 0.07^{\mathrm{a}}$ & $81.26 \pm 1.80^{\mathrm{a}}$ \\
\hline \multicolumn{4}{c}{${ }^{1}$ Calculated as: $100-(\%$ residual moisture + \% protein +\% ether extract + \% ash). } \\
\multicolumn{4}{c}{ Different letters indicate significant differences (p<0.05) }
\end{tabular}

Currently, their consumption has increased due to physiological benefits and/or diseases risk reduction. Presented in Table 1 are the results obtained for the proximate chemical composition of the different parts analyzed based on dry matter ( $\mathrm{M}_{\mathrm{S}}$ : seed, $\mathrm{M}_{\mathrm{F} / \mathrm{s}}$ : seedless fruit and $\mathrm{M}_{\mathrm{F}}$ : whole fruit). In seeds, the content of proteins, fatty matter and crude fiber 
are higher than in the other parts analyzed, being: $4.35 \pm 0.05,7.69 \pm 0.55$ and $11.66 \pm 0.28(\mathrm{~g} / 100 \mathrm{~g})$, respectively, values that are similar to the informed by Jiménez et al. [20]. However, it should be noted that there are very few studies that have determined the chemical composition of this seed. Regarding the whole fruit, the values found are in agreement with the reported by Demir et al. [21] , and similar to members of the Rosaceae family such as apple [22]. It is noteworthy the content of proteins in the studied sweet briar rose when compared with conventional fruits, whose values vary between $0.1-1.5 \mathrm{~g} \%$ [23]. The highest amount of ashes is found in the seedles fruits ( $7.11 \pm 0.06 \%)$; this high value reflects the rich content of minerals in this fruit [24].

Analyzing the lipid profile of the flour from $\mathrm{M}_{\mathrm{S}}$ and $\mathrm{M}_{\mathrm{F}}$ (Table 2), it is observed the predominance of unsaturated fatty acids, with a percentage of $93.09 \%$ and $86.23 \%$, respectively. In general, the contribution of saturated and unsaturated fatty acids is higher in the whole fruit than in the seed.

Table 2 Fatty acids composition (\% of total lipids) of flour from R. rubiginosa L.

\begin{tabular}{|c|c|c|c|}
\hline Carbon atoms & Acids & Ms & $\mathbf{M}_{\mathbf{F}}$ \\
\hline 12:0 & Lauric & ND & $0.2 \pm 0.08$ \\
\hline 14:0 & Myristic & ND & $0.2 \pm 0.07$ \\
\hline 16:0 & Palmitic & $3.85 \pm 0.07^{a}$ & $6.00 \pm 0.14^{\mathrm{b}}$ \\
\hline $17: 0$ & Margaric & $0.10 \pm 0.02^{\mathrm{a}}$ & $0.10 \pm 0.01^{\mathrm{a}}$ \\
\hline 18:0 & Stearic & $2.00 \pm 0.005^{\mathrm{a}}$ & $2.81 \pm 0.02^{\mathrm{b}}$ \\
\hline 20:0 & Arachidic & $0.91 \pm 0.21^{\mathrm{a}}$ & $1.07 \pm 0.10^{\mathrm{a}}$ \\
\hline 22:0 & Behenic & $0.20 \pm 0.007^{a}$ & $0.43 \pm 0.021^{\mathrm{b}}$ \\
\hline $24: 0$ & Lignoceric & $0.11 \pm 0.007^{a}$ & $0.40 \pm 0.02^{\mathrm{b}}$ \\
\hline $16: 1$ & Palmitoleic & $0.12 \pm 0.005^{\mathrm{a}}$ & $0.21 \pm 0.01^{b}$ \\
\hline 18:1 & Oleic & $15.41 \pm 0.15^{\mathrm{a}}$ & $16.92 \pm 0.07^{b}$ \\
\hline 18:1 & Cis-Vaccenic & $0.71 \pm 0.03^{\mathrm{a}}$ & $0.80 \pm 0.03^{b}$ \\
\hline $20: 1$ & Gondoic & $0.22 \pm 0.01^{\mathrm{a}}$ & $0.63 \pm 0.04^{b}$ \\
\hline $22: 1$ & Erucic & $0.10 \pm 0.02^{\mathrm{a}}$ & $0.81 \pm 0.07 \mathrm{~b}$ \\
\hline $18: 2$ & Linoleic & $43.10 \pm 1.3^{\mathrm{a}}$ & $37.61 \pm 1.9^{b}$ \\
\hline $18: 2$ & Trans & $0.10 \pm 0.01$ & ND \\
\hline $20: 2$ & Eicosadienoic & $0.10 \pm 0.01$ & ND \\
\hline $18: 3$ & $\alpha$-Linolenic & $32.63 \pm 1.25^{\mathrm{a}}$ & $28.64 \pm 0.91^{\mathrm{b}}$ \\
\hline $18: 3$ & trans & $0.50 \pm 0.02^{\mathrm{a}}$ & $0.41 \pm 0.01^{b}$ \\
\hline $20: 3$ & 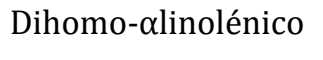 & $0.10 \pm 0.02^{\mathrm{a}}$ & $0.10 \pm 0.01^{\mathrm{a}}$ \\
\hline $20: 4$ & $\alpha$-Arachidonic & ND & $0.10 \pm 0.015$ \\
\hline \multicolumn{2}{|l|}{ Unidentified } & ND & 2.7 \\
\hline \multicolumn{2}{|c|}{ Saturated fatty acids } & 7.17 & 11.21 \\
\hline \multicolumn{2}{|c|}{ Unsaturated fatty acids } & 93.09 & 86.23 \\
\hline \multicolumn{2}{|c|}{ Saturated/unsaturated ratio } & 0.08 & 0.13 \\
\hline
\end{tabular}

The fatty acids that result indispensable to promote growth and good functioning of the animal organism are: linoleic acid (18:2 n-6) and linolenic acid (18:3 n-3). Highlighted in this work is the content of linoleic acid (43.10-37.61\%), 
followed by $\alpha$-linolenic acid (32.63-28.64\%) and oleic acid (15.41-16.92\%) in $\mathrm{M}_{\mathrm{s}}$ and $\mathrm{M}_{\mathrm{F}}$, respectively, values that are similar to the reported by Eggers et al. [25], Jimenez et al. [20] and Magdalena et al. [26].

In general, seed oils are the most important source of linoleic acid, with a poor contribution of linolenic acid except for some oils that provide interesting values, such as canola (12\%), soy (7\%), rapeseed (11\%), walnut (10\%), among others [27]. In this study, the content of linolenic acid determined is significant, which results relevant given that the dietary intake of this fatty acid is associated with a lower mortality risk due to cardiovascular diseases, as well as a lower prevalence, probability of carotid plaques, and a lower risk of carotid atherosclerosis [28]. These fatty acids have to be inevitably provided by the diet since they cannot be synthetized by the animal organisms, including humans, so that the production of oils from sweet briar rose becomes an alternative to increase the consumption of essential fatty acids [29].

Polyphenols are low-molecular-weight phytochemicals essential for the human being; they constitute one of the secondary metabolites present in fruits, vegetables and grains. The physiological function of Rosaceae fruits can be attributed in part to their abundance in phenolic compounds, which have a wide spectrum of biochemical activities, such as antimutagenic, anticarcinogenic and antioxidant effects, as well as the capacity to modify the genetic expression [30]. Natural polyphenols can go from simple molecules (phenolic acid, phenylpropanoids, flavonoids), up to highly polymerized compounds (lignin, tannins). The antioxidant compounds analyzed in the metabolic extracts of sweet briar rose are presented in Table 3.

Table 3 Content of total phenols and anthocyanins of $R$. rubiginosa $\mathrm{L}$.

\begin{tabular}{|c|c|c|c|}
\hline Determination & Ms & $\mathbf{M}_{\mathbf{F} / \mathbf{S}}$ & $\mathbf{M F}_{\mathbf{F}}$ \\
\hline Total phenols ${ }^{1}$ & $63.5 \pm 1.72^{\mathrm{a}}$ & $116.21 \pm 2.12^{\mathrm{b}}$ & $119.11 \pm 1.58^{b}$ \\
\hline Anthocyanins ${ }^{2}$ & $5.24 \pm 0.63^{a}$ & $1.74 \pm 0.21^{b}$ & $2.67 \pm 0.30^{\mathrm{b}}$ \\
\hline
\end{tabular}

The content of total phenols analyzed in the three samples allows to observed that the values obtained for the whole fruit and seedless fruit (119.11 and $116.21 \mathrm{mg} / 100 \mathrm{~g} \mathrm{dw}$ of gallic acid, respectively), are significantly higher than for the seed ( 63.5 and $\mathrm{mg} / 100 \mathrm{~g}$ dw of gallic acid). These values are comparable with the reported by Jaime-Guerrero et al. [31]. In general, the level of anthocyanins in fruits is much higher than in vegetables, being berries and blackcurrants more rich diverse. This bioactive can be found in all parts of the plans; although it mainly accumulates in flowers and fruits, it is also present in leaves, stems and storage organs. In this study, the highest anthocyanins content is in the seed: $5.24 \mathrm{mg} / 100 \mathrm{~g} \mathrm{dw}$ cyanidin-3-glucoside, which is comparable to the reported by Mabellini et al., [7] (2.8 to 3.1 $\mathrm{mg} / 100 \mathrm{~g}$ cyanidin-3-glucoside), who do not report data on the whole fruit.

Table 4 Antioxidant activity of $R$. rubiginosa L. methanolic extracts

\begin{tabular}{|c|c|c|c|}
\hline Determination & Ms & $\mathbf{M}_{\mathbf{F} / \mathbf{S}}$ & $\mathbf{M F}_{\mathbf{F}}$ \\
\hline DPPH inhibition (\%) & $93.37 \pm 0.85^{\mathrm{a}}$ & $93.76 \pm 0.27^{\mathrm{a}}$ & $93.47 \pm 0.27^{a}$ \\
\hline NO inhibition (\%) & $29.36 \pm 5.28^{a}$ & $49.42 \pm 4.87^{b}$ & $33.57 \pm 5.83^{a}$ \\
\hline$\beta$-carotene inhibition (\%) & $29.50 \pm 3.50^{\mathrm{a}}$ & $21.5 \pm 4.27^{b}$ & $22.5 \pm 4.75^{\mathrm{ab}}$ \\
\hline
\end{tabular}

In vegetables, the antioxidant capacity is directly related to the content of bioactive compounds. The phytochemicals natural complexity does not allow for the antioxidant activity to be evaluated by a simple technique; therefore, we use the following spectrophotometric methods: DPPH radical-scavenging activity to evaluate the antioxidants capacity in capturing free radicals; nitric oxide (NO) scavenging activity, which reflects the ability of the samples to remove free radicals derived from NO; and $\beta$-carotene bleaching method, which is considered as a model method for the study of the 
antioxidants effect on the peroxidation of membrane lipids. The antioxidant capacity of the three studied samples is presented in Table 4.

The DPPH radical-scavenging method is the most used due to its practicality and efficiency, and is a measurement of the scavenging activity of reactive species by the antioxidants. The inhibition percentage does not present significant differences among the three studied samples: $93.37 ; 93.76$ and $93.47 \%$, values that are similar to the reported by Guerrero et al. [31] for two sweet briar rose cultivars (94.4 and 95.35\%), which are values considered as with high radical-scavenging activity.

The relationship between polyphenols content and antioxidant activity presented a linear correlation with $\mathrm{R}^{2}=0.587$ (Figure 1). Probably, the high DPPH inhibition percentage is a product of other antioxidant components present in the samples, such as some minerals (Se, $\mathrm{Zn}$ and Mg) and vitamins (vit. C). Roman et al. [32], reported higher correlation values, $\mathrm{R}^{2}=0.713$.

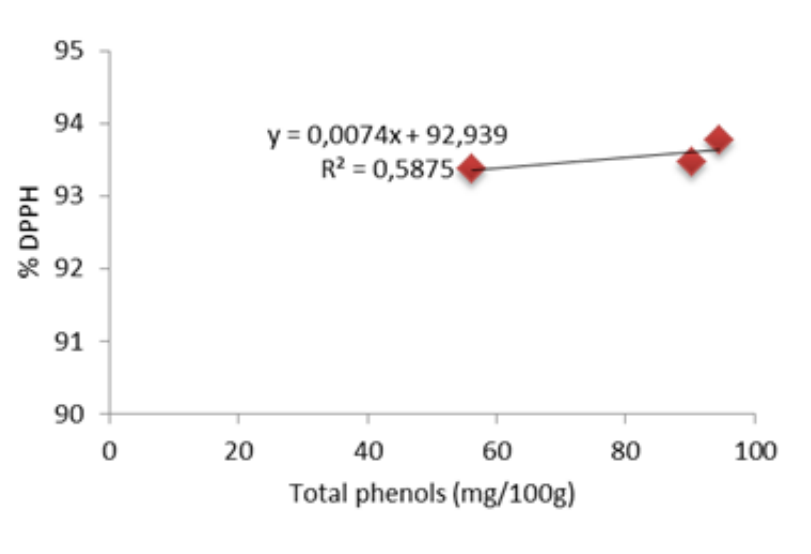

Figure 1 Correlation between total phenols content and the DPPH assay of $R$. rubiginosa L. methanolic extracts

Nitric oxide is generated in biological tissues by the nitric oxide synthase enzyme. The studied methanolic extracts presented a moderate activity in the nitric oxide scavenging, being the highest value for the seedless fruit, whose inhibition percentage is of $49.42 \%$ (Table 4 ). The relationship between polyphenols content and nitric oxide scavenging activity presented a linear correlation with $\mathrm{R}^{2}=0.5389$ (Figure 2).

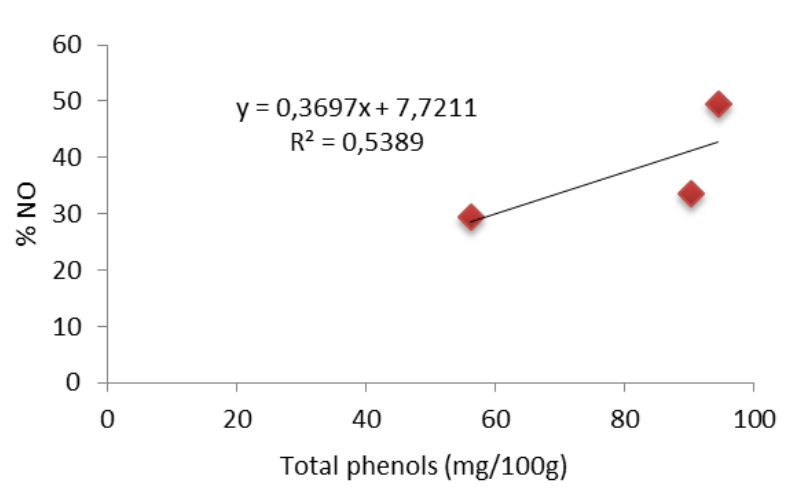

Figure 2 Correlation between total phenols content and the NO assay of R. rubiginosa L. methanolic extracts

Another of the methods applied to determine the antioxidant activity was the $\beta$-carotene bleaching method, where $\beta$ carotene oxidizes in the presence of linoleic acid. In this case, it is observed that the flour of sweet briar rose seed is the one with the highest antioxidant activity $(29.50 \%)$, with a significant difference with respect to the other samples evaluated, being negative the correlation with total phenols (Figure 3). 


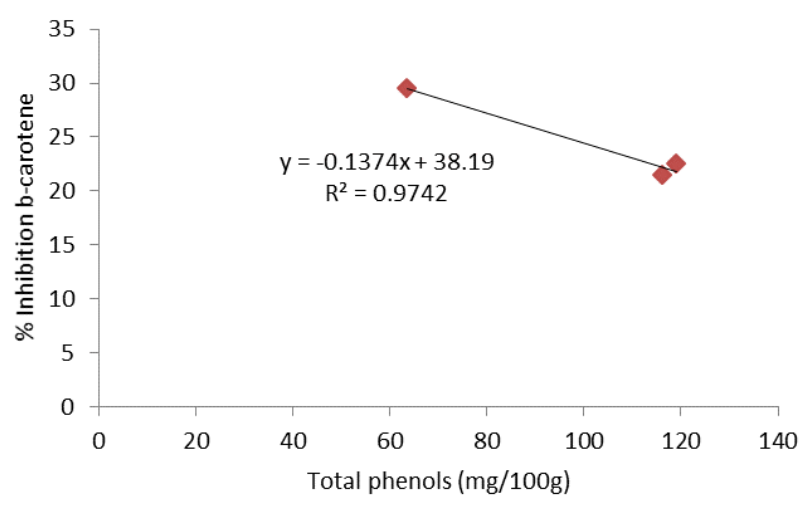

Figure 3 Correlation between total phenols content and the $\% \beta$-carotene inhibition of $R$. rubiginos $a$ L. methanolic extracts

Regarding the anthocyanins, a high correlation is observed with respect to the $\beta$-carotene bleaching, $\mathrm{R}^{2} 0.97$ (Figure 4), being this correlation negative with the other two antioxidant activity evaluation methods. Therefore, the inhibition of lipids peroxidation could be mainly attributed to the presence of anthocyanins.

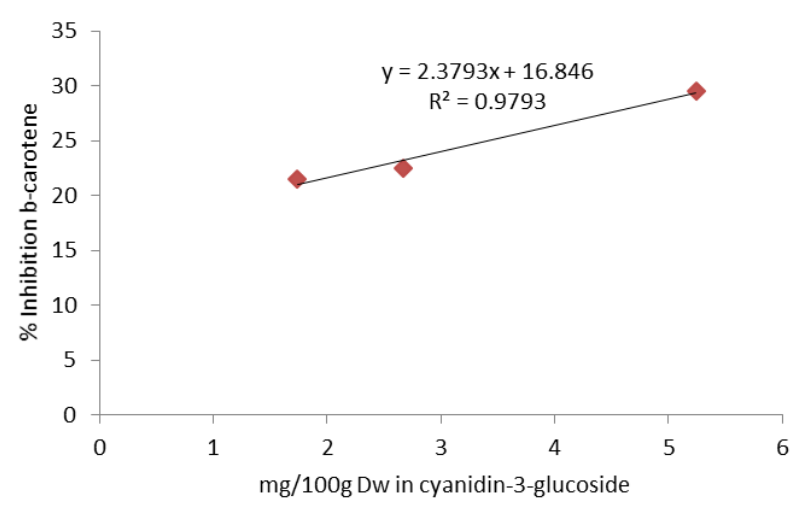

Figure 4 Correlation between anthocyanins content and the $\% \beta$-carotene Inhibition of $R$. rubiginosa L. methanolic extracts

\section{Conclusion}

This study indicates that R. rubiginosa (Rosa eglanteria L.) from this region is a potential contributor of phenols and anthocyanins, which contribute to its antioxidant activity, as well as having an interesting essential fatty acids profile associated to a lower risk of cardiovascular diseases, due to the presence of linoleic and linolenic acid. The high content of unsaturated fatty acids is promising from the nutritional point of view as well as due to its pharmaceutical properties. On the other hand, the protein content is higher than in most conventional fruits, and the high percentage of ashes indicates a very important minerals source. The results obtained are a contribution to the knowledge on the fruit nutritional properties, which will allow to diversify its consumption and use as a food resource with potential antioxidant activity, able of being considered as an emerging functional food.

\section{Compliance with ethical standards}

\section{Acknowledgments}

The authors would like to thank the National University of San Luis for the financing of this study.

\section{Disclosure of conflict of interest}

There authors declare there is no conflict of interest. 


\section{Statement of ethical approval}

The present research work does not contain any studies performed on animals/humans subjects by any of the authors.

\section{References}

[1] Alexandratos N and Bruinsma J. (2012). World agriculture towards 2030/2050. Revision. Roma, FAO.

[2] GBD 2015. Risk Factors Collaborators. (2016). Global, regional, and national comparative risk assessment of 79 behavioral, environmental and occupational, and metabolic risks or clusters of risks, 1990-2015: a systematic analysis for the Global Burden of Disease Study 2015. Lancet, 388(10053), 1659-1724.

[3] American Dietetic Association. (2009). Position of the American dietetic association: functional foods. Journal of the American Dietetic Association, 109, 735-746.

[4] Binns N. (2009). Perspectives on ILSI's International Activities on Functional Foods. Report commissioned by the ILSI Europe Functional Foods Task Force. 1-57.

[5] Moure A, Cruz JM, Franco D, Dominguez JM, Sineiro J, Dominguez H, Nunez MJ and Parajo JC. (2001). Natural antioxidants from residual sources. Food Chemistry, 72,145-171.

[6] Contreras-Calderón J, Calderón-Jaimes L, Guerra-Hernández E and García-Villanova B. (2010). Antioxidant capacity, phenolic content and vitamin C in pulp, peel and seed from 24 exotic fruits from Colombia. Food Research International, 44 (7), 2047-2053.

[7] Mabellini A, Ohaco E, Ochoa MR, Kesseler G, Marquez CA and De Michelis A. (2011). Chemical and Physical Characteristics of Several Wild Rose Species Used as Food or Food Ingredient. International Journal of Industrial Chemistry, 2 (3), 158-171.

[8] Halvorsen BL, Holte K, Myhrstad MCW, Barikmo I, Hvattum E, Remberg SF, Wold AB, Haffner K, Baugerød H, Andersen LF, Moskaug Jø, Jacobs DR and Blomhoff RA. (2002). Systematic screening of total antioxidants in dietary plants. The Journal of Nutrition, 132, 461-471.

[9] Olsson ME, Gustavsson K.E, Andersson S, Nilsson Å and Duan RD. (2004). Inhibition of cancer cell proliferation in vitro by fruit and berry extracts and correlations with antioxidant levels. Journal of Agricultural and Food Chemistry, 52, 7264-7271.

[10] Pirone BN, Ochoa MR, Kesseler AG and De Michelis A. (2007). Chemical Characterization and Evolution of Ascorbic Acid Concentration during Dehydration of Rosehip (Rosa eglanterid) Fruits. American Journal of Food Technology, 2, 377-387.

[11] AOAC (2012) Official Methods of Analysis. Official Methods of Analysis of the AOAC International, 19th ed. Gaithersburg, MD, USA.

[12] AOCS Ce 1k-09. (2009). Direct Methylation of Lipids in Foods for the Determination of Total Fat, Saturaded, cisMonounsaturated, cis-Polyunsaturated, and trans Fatty Acids by Gas Chromatograph. ISO 12966-4:2015. Animal and vegetable fats and oils. Gas chromatography of fatty acid methyl esters. Part 4: Determination by capillary gas chomatograph.

[13] Vinson J, Proch, J and Bose P. (2001). Determination of the quantity and quality of polyphenol antioxidants in foods and beverages. Methods Enzymol, 335,103-14.

[14] Singleton V and Rossi J. (1965). Colorimetry of total phenolics with phosphomolybdic phosphotungstic acid reagents. American Journal of Enology and Viticulture, 16,144-158.

[15] Cheng G and Breen P. (1991). Activity of phenylalanine ammonia-lyase (PAL) and concentrations of anthocyanins and phenolics in developing strawberry fruit. Journal of the American Society for Horticultural Science, 116, 865869.

[16] Brand-Williams W, Cuvelier M and Berset C. (1995). Use of free radical method to evaluate antioxidant activity. LWT - Food Science and Technology, 28 (1), 25-30.

[17] Koleva I, van Beek T, Linssen J, de Groot A and Evstatieva L. (2002). Screening of plant extracts for antioxidant activity: a comparative study on three testing methods. Phytochemical Analysis, 13(1), 8-17.

[18] Marcocci L, Packer L, Droy Lefaix M, Sekaki A and Garde's Albert M. (1994) Antioxidant action of Ginkgo biloba extract EGb 761. Methods Enzymol, 234, 462-475. 
[19] Saija A, Tomaino A, Lo Cascio R, Trombetta D, Proteggente A, De Pasquale A, Uccella N and Bonina F. (1999). Ferulic and caffeic acids as potential protective agents against photooxidative skin damage. Journal of the Science of Food and Agriculture, 79, 476-480.

[20] Jiménez PP, Masson SL and Quitral RV. (2013). Chemical composition of chia seeds, flaxseed and rosehip and its contribution in omega-3 fatty acids. Chilean nutrition magazine, 40 (2), 155-160.

[21] Demir F and Özcan M. (2001). Chemical and Technological Properties of Rose (Rosa canina L.) Fruits Grown Wild in Turkey. Journal of Food Engineering, 47, 333-336.

[22] Gbago O, Huaiyuan Z, Erasto M, Mohamed D and Yuanda S. (2014) Chemical Composition, Nutritional Properties and Antioxidant Activity of Monkey Apple (Anisophyllea laurina R. Br. ex Sabine). Journal of Food and Nutrition Research, 2(6), 281-287.

[23] Morillas-Ruiz JM and Delgado-Alarcón JM. (2012). Nutritional analysis of plant foods with different origins: Evaluation of antioxidant capacity and total phenolic compounds. Clinical Nutrition and Hospital Dietary Journal, 32(2), 8-20.

[24] Aguirre G, Loza M, Gasquez J, Fusco MF, Sosa A, Ciuffo GM and Ciuffo LEC. (2016). The potentiality of non-timber forest products. Fruit availability, phytochemical properties of Rosa rubiginosa L. Rose hips. American Journal of Plant Sciences, 7, 2272-2287.

[25] Eggers R, Ambrogi A and Von Schnitzler J. (2000). Special features of scf solid extraction of natural products: deoiling of wheat gluten and extraction of rose hip oil. Technical University of Hamburg - Hamburg, Germany. Brazilian Journal of Chemical Engineering, 17, 1-8.

[26] Magdalena AP, Katarzyna K, Wojakowska A, Kulma A and Grajeta H. (2015). Characteristics of rose hip (Rosa canina L.) cold-pressed oil and its oxidative stability studied by the differential scanning calorimetry method. Food Chemistry, 188, 459-466.

[27] Jimenez P, Masson L, Barriga A, Chávez J and Robert P. (2011). Oxidative stability of oils containing olive leaf extracts obtained by pressure, supercritical and solvent-extraction. European Journal of Lipid Science and Technology, 113, 497-505.

[28] Djousse L, Hunt SC, Arnett DK, Province MA, Eckfeldt JH and Ellison J. (2003). Dietary linolenic acid is inversely associated with plasma triacylglycerol. The American Journal of Clinical Nutrition, 78, 1098-1102.

[29] Pita Martín de Portela M L. (2006). Energy and macronutrients in the nutrition of the 21st century. The Medical Press Argentina, Buenos Aires (Argentina).

[30] Nakamura Y, Watanabe S, Miyake N, Kohno H and Osawa T. (2003). Dihydrochalcones: evaluation as novel radical scavenging antioxidants. Journal Agriculture Food Chemistry, 51, 3309-3312.

[31] Guerrero C J, Ciampi Pl, Castilla CA, Medel SF, Schalchli SH, Hormazabal UE, Bensch T E and Alberdi L M. (2010). Antioxidant capacity, anthocyanins, and total phenols of wild and cultivated berries in Chile. Chilean Journal of Agricultural Research, 70(4), 537-544.

[32] Roman I, Stănilă A, and Stănilă S. (2013). Bioactive compounds and antioxidant activity of Rosa canina L. biotypes from spontaneous flora of Transylvania. Chemistry Central Journal, 7 (1), 73.

\section{How to cite this article}

Jofré M, Razzeto G, Escudero N and Albarracín G. (2017). Chemical evaluation, bioactive compounds and antioxidant activity of Rosa rubiginosa L. fruit and seed. GSC Biological and Pharmaceutical Sciences, 1(3), 44-53. 